\title{
Secondary magnetizations from the Clinton-type iron ores of the Silurian Red Mountain Formation, Alabama
}

\author{
Hervé Perroud * and Rob Van der Voo \\ Department of Geological Sciences, the University of Michigan, Ann Arbor, MI 48109 (U.S.A.)
}

Received May 6, 1983

Revised version received November 8, 1983

\begin{abstract}
From 27 (out of a total of 29) sites a characteristic pre-folding magnetization has been obtained with $D=150^{\circ}$, $I=+20^{\circ}, \alpha_{95}=3.5^{\circ}$, and paleopole at $38^{\circ} \mathrm{N}, 132^{\circ} \mathrm{E}$. However, we conclude from a bedding-error test and a conglomerate test, as well as from descriptions of the hematite as a replacement mineral, that the magnetization is a (late) post-depositional chemical remanent magnetization. The age constraints on the magnetization, between Middle Silurian and Early Permian, can be refined by a comparison with the apparent polar wander path for cratonic North America; this comparison suggests a Late Carboniferous age for the magnetization and the hematite, which constitutes the principal component of the iron ores. Similar Late Paleozoic remagnetizations have been noted in other Appalachian and mid-continent formations and suggest a widespread, but as yet ill-defined mechanism for the remagnetization. It is tempting to correlate this event with the early phases of the Alleghenian orogeny in Carboniferous times and with possible fluid migrations resulting from the tectonism.
\end{abstract}

\section{Introduction}

The mid-Paleozoic segments of the North American apparent polar wander path are not well defined, although in recent years several Silurian $[1,2]$ and one Early Devonian paleopole 5 [3] have been determined. Although the ancient Appalachian margin sequence has been subsequently deformed during the Alleghenian orogeny, there is little question that these formations of the Valley and Ridge Province formed part of cratonic North America, and the additional advantage of possible fold tests to constrain the age of the magnetization prompted us to undertake an investigation of the

\footnotetext{
* Permanent address: Centre Armoricain d'Etude Structurale des Socles (CAESS), L.P. 466 of the C.N.R.S., Institut de Géologie, Université de Rennes, 35042 Rennes Cédex, France.
}

Red Mountain Formation of Lower to Middle Silurian age in Alabama [4-6].

Previous paleomagnetic work has been published for this formation in the early days of paleomagnetism [7] but the resulting paleopole was based on only 7 samples, studied without extensive demagnetization techniques. In addition, Buchan and Hodych described some of their results in a presentation at the meeting of the American Geophysical Union [8,29].

From these preliminary investigations, it appeared that the Red Mountain carries a pre-folding magnetization; yet, its paleopole does not fall near to other Silurian paleopoles. Consequently, we organized our sampling to provide us with additional field tests, in order to provide constraints on the age of magnetization.

The geological setting of the sampling area is fairly well known [9-12]; where necessary, we discuss significant details of the geology in the following sections. 


\section{Sampling and laboratory procedures}

From 29 sites (Fig. 1), 200 samples have been drilled in the field and oriented with a Brunton compass. Sites were selected to provide fold-, conglomerate-, and bedding-error tests [13,14], and to investigate as many different lithologies as possible. The lithologic facies range from typical hematitic ore beds, such as for example the four seams in the Red Mountain outcrop at the expressway just south of Birmingham (Fig. 1), to fine-grained, dark-grey to reddish-grey hematitic sandstones; we will refer in this paper to these two lithologies as the "red" and the "grey" sites. The generation of hematite in these Clinton-type iron ores has been shown $[15,16]$ to be associated with extensive replacement textures of calcitic fossil fragments, which form the principal constituent of the ores. The most abundant fossils are bryozoa, brachiopods, trilobites, echinoderms, ostracod fragments and fecal pellets, which are all typical of the Middle Silurian (e.g., Pentamerus oblongus).

The two conglomerate lenses sampled (sites 20 and 21) are formed by discoid cobbles of laminated sandstone or limestone, up to $10 \mathrm{~cm}$ in length, and set in a dark-red hematitic and calcitic matrix; they are thought to be derived from layers of the

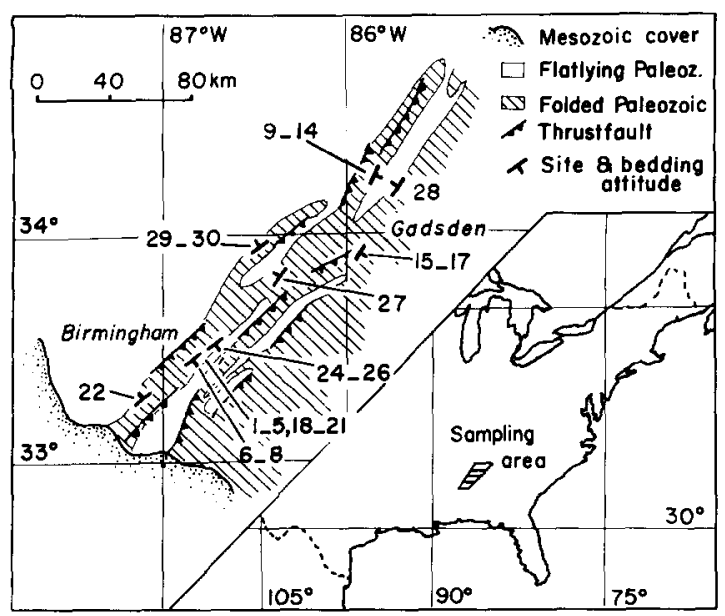

Fig. 1. Schematic geologic map of the sampling area with sites indicated by the strike and dip symbols and their site numbers, corresponding to those of Table 1.
Red Mountain Formation itself [9]. Cross bedding is fairly common, with foreset dips up to $20^{\circ}$, and cross beds were sampled at two sites (18 and 19) with the same lithologies as the other red sites.

The Red Mountain Formation in this south Appalachian setting is representative of the North American cratonic margin and was deformed during the Late Carboniferous/Early Permian Alleghenian orogeny, that involved folding and thrusting [12]. In the Birmingham area, the folds are asymmetric, with gentle eastward dips and nearly vertical westerly limbs, the latter being located near the thrust planes, and possibly involving considerable structural complexities. As a consequence, the usefulness of the steeply dipping sites on the westerly limbs is limited, albeit essential for Graham's fold test [13].

Samples have been cut in the laboratory to standard $2.4 \mathrm{~cm}$ height, and natural remanent magnetizations (NRM's) have been measured with either an ScT cryogenic magnetometer or a Schonstedt spinner magnetometer. Alternating field (AF) demagnetizations were performed with a Schonstedt AF demagnetizer, and thermal demagnetizations were done in a Schonstedt furnace, with cooling in a residual field of less than $10 \mathrm{nT}$. A majority of the specimens were progressively demagnetized, with up to 10 steps, but when univectorial magnetizations became apparent treatment involved fewer steps. Chemical demagnetizations were performed following the procedures of Park [17] and Henry [18]. Many samples contained calcitic cement, so acid concentrations were chosen at low levels until no further calcite dissolution became apparent, whereupon acid normality was increased gradually up to $10 \mathrm{~N}$. During the first steps leaching had to be performed in a fume hood, but after calcite dissolution was completed the samples were leached in field-free space (usually after 10 hours of leaching).

Demagnetization results have been interpreted with the aid of Zijderveld [19] diagrams as well as great-circle analysis [20]. Isothermal remanent magnetization (IRM) acquisition experiments were carried out up to $5 \mathrm{~T}$ with a cryogenic magnet, involving pairs of leached and non-leached samples. Site-mean directions are given in Table 1 with their associated statistical parameters. 
TABLE 1

Site-mean paleomagnetic directions

\begin{tabular}{|c|c|c|c|c|c|c|c|}
\hline Site & $N / N_{0}$ & Treatment & $\begin{array}{l}\text { Before T.C. } \\
\mathrm{decl} / \text { incl }\end{array}$ & $\begin{array}{l}\text { After T.C. } \\
\text { decl/incl }\end{array}$ & $k$ & $\alpha_{95}$ & Comments \\
\hline 1 & $9 / 9$ & $\mathrm{AF}, \mathrm{th}, \mathrm{ch}$ & $154 /+31$ & $154 /+12$ & 446 & 2.4 & \\
\hline 2 & $8 / 8$ & $A F, t h, c h$ & $154 /+36$ & $154 /+12$ & 102 & 5.5 & \\
\hline 3 & $8 / 8$ & $A F, t h, c h$ & $154 /+36$ & $154 /+13$ & 324 & 3.1 & \\
\hline 4 & $7 / 7$ & $A F$, th, ch & $157 /+38$ & $154 /+13$ & 87 & 6.5 & grey ss. \\
\hline 5 & $7 / 8$ & th, ch & $152 /+37$ & $151 /+14$ & 73 & 7.1 & 1 sample destroyed by $\mathrm{HCl}$ \\
\hline 6 & $10 / 10$ & th, ch & $149 /+39$ & $148 /+22$ & 596 & 2.0 & \\
\hline 7 & $7 / 9$ & th, ch & $151 /+44$ & $152 /+25$ & 862 & 2.1 & 1 core rejected (orientation?) \\
\hline 8 & $6 / 6$ & th, ch & $152 /+38$ & $154 /+22$ & 146 & 5.6 & \\
\hline 9 & $12 / 12$ & $\mathrm{AF}, \mathrm{th}, \mathrm{ch}$ & $159 /+39$ & $156 /+23$ & 83 & 4.8 & grey ss. (see Fig. 3) \\
\hline 10 & $4 / 4$ & th & $160 /+19$ & $159 /+3$ & 829 & 3.2 & \\
\hline 11 & $8 / 8$ & $\mathrm{AF}, \mathrm{th}, \mathrm{ch}$ & $159 /+44$ & $151 /+31$ & 35 & 9.5 & grey ss. \\
\hline 12 & $9 / 9$ & Af, th, ch & $162 /+39$ & $155 /+29$ & 149 & 4.2 & grey ss. \\
\hline 13 & $7 / 7$ & th, $\mathrm{ch}$ & $158 /+31$ & $154 /+20$ & 130 & 5.3 & \\
\hline 14 & $0 / 9$ & $\mathrm{AF}, \mathrm{th}, \mathrm{ch}$ & - & - & - & - & rejected; no consistency \\
\hline 15 & $6 / 6$ & $A F$, th, ch & $154 /+48$ & $147 /+24$ & 11 & 21.0 & grey ss. \\
\hline 16 & $6 / 6$ & $\mathrm{AF}, \mathrm{th}, \mathrm{ch}$ & $159 /+54$ & $147 /+23$ & 70 & 8.1 & grey ss. \\
\hline 17 & $4 / 4$ & $A F$, th, ch & $141 /+53$ & $136 /+20$ & 31 & 17.0 & grey ss. \\
\hline 18 & $12 / 12$ & th & $148 /+37$ & $148 /+17$ & 548 & 1.9 & bedding-error test (Fig. 5) \\
\hline 19 & $11 / 11$ & th & $151 /+42$ & $150 /+25$ & 770 & 1.6 & bedding-error test (Fig. 5) \\
\hline 20 & $12 / 13$ & th & $149 /+43$ & $148 /+17$ & 169 & 3.3 & conglomerate test (Fig.6) \\
\hline 21 & $13 / 13$ & th & $151 /+42$ & $149 /+23$ & 171 & 3.2 & conglomerate test (Fig. 6) \\
\hline 22 & $14 / 14$ & th, ch & $222 /-47$ & $203 /+19$ & 150 & 3.3 & excluded from overall mean \\
\hline 24 & $11 / 11$ & th & $138 /+7$ & $138 /+11$ & 136 & 3.9 & \\
\hline 25 & $12 / 12$ & th & $142 /+18$ & $141 /+31$ & 397 & 2.2 & \\
\hline 26 & $8 / 8$ & th & $147 /+17$ & $143 /+18$ & 404 & 2.8 & \\
\hline 27 & $7 / 7$ & th & $169 /-44$ & $168 /+39$ & 237 & 3.9 & \\
\hline 28 & $4 / 8$ & th & $143 /+1$ & $147 /+35$ & 294 & 5.4 & 4 samples give only VRM \\
\hline 29 & $9 / 9$ & th & $151 /-3$ & $151 /+10$ & 170 & 4.0 & \\
\hline 30 & $9 / 9$ & th & $148 /+3$ & $149 /+16$ & 80 & 5.8 & \\
\hline \multirow{2}{*}{\multicolumn{3}{|c|}{ Mean $27 / 29$}} & $152 /+30$ & $150 /+20$ & & & excluding sites 14,22 . \\
\hline & & & $k=14$ & $k=64$ & & & \\
\hline
\end{tabular}

$N$ is the number of samples used in the statistical analysis, versus $N_{0}$, which is the total number of samples measured; T.C. denotes correction for the tilt of the strata; decl/incl are the declination and inclination in degrees; $k$ and $\alpha_{95}$ are the statistical parameters associated with the mean direction, giving unit weight to $N$.

\section{Paleomagnetic results}

\subsection{Comparison of magnetic behavior in red and grey samples}

Zijderveld plots are displayed in Figs. 2 and 3. Typical behavior of the red sites (Fig. 2) was characterized by univectorial decay to the origin in thermal as well as chemical demagnetization. The directions are mostly southeasterly, with inclinations before structural correction ranging from intermediate downward to intermediate upward. A composite nature of the total NRM of these samples is unlikely, as blocking temperature spectra as well as solubility spectra would have to be completely overlapping in the case of two magnetization components. Maximum blocking temperatures and the coincidence of magnetization decay with the disappearance of the red coloration are strongly suggestive of hematitic pigment as the principal magnetic carrier in the red sites. Hence, we conclude that a chemical origin of the magnetization in these red sites is likely, although the blocking temperature spectra are rather discrete, 

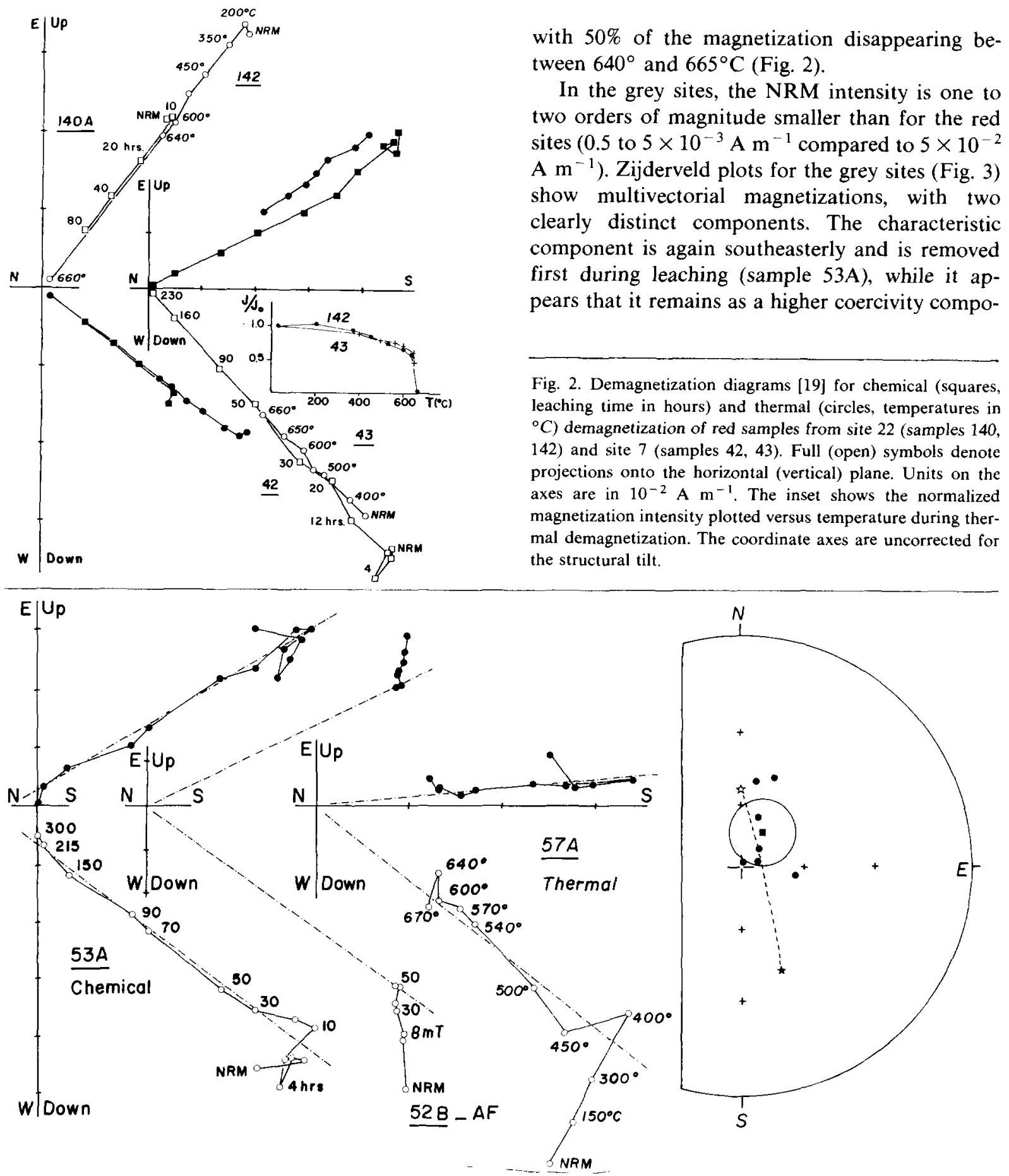

Fig. 3. Demagnetization diagrams (as in Fig. 2) for chemical, AF, and thermal treatments of grey samples from site 9, and a stereoplot of the recent overprint magnetizations of this site. Units on the axes are in $10^{-3} \mathrm{~A} \mathrm{~m}^{-1}$. The full star in the stereoplot is the mean direction of the characteristic magnetizations for this site, and the open star is the present-day magnetic field direction. All symbols are plotted on the lower hemisphere, and all plots are without correction for the structural tilt. The square represents the mean of the recent overprint directions, plotted with its circle of $95 \%$ confidence. 
nent in the samples after AF demagnetization up to $50 \mathrm{mT}$ (sample 52B). Thermal demagnetization reveals this magnetization at higher blocking temperatures, characteristic of hematite, after removal of a low-blocking temperature component aligned with the present-day field direction (sample 57A). Where the latter component could be isolated, it usually displays a steeply inclined north to northeasterly direction. Fig. 3 displays a plot of these directions observed in site 9 , with mean $D=33^{\circ}$, $I=+70^{\circ}, \alpha_{95}=16^{\circ}, N=7$ specimens. We intermagnetization. However, in some cases magnetizations of samples from the grey sites appear to decay linearly, but not to the origin, and this component could not be isolated (e.g., sample 53A in Fig. 3). In these cases great-circle analysis was pret this direction as a viscous present-day field

performed. Often the in-situ greatcircles pass through the characteristic direction as well as the present-day field direction, but not always: however, the only best-fitting intersections obtained in this procedure are those that reveal the characteristic southeasterly direction of the other grey sites as well as all the red sites. Th efact that no other convergence (before or after structural correction) was observed, indicates that some of the unresolved components are of random orientation in addition to those with an alignment parallel to the present-day field. In summary, the only consistent magnetization other than a present-day field direction (e.g., site 9 in Fig. 3) is the southeasterly direction that is characteristic for the red sites as well.

The IRM acquisition experiments (Fig. 4) show

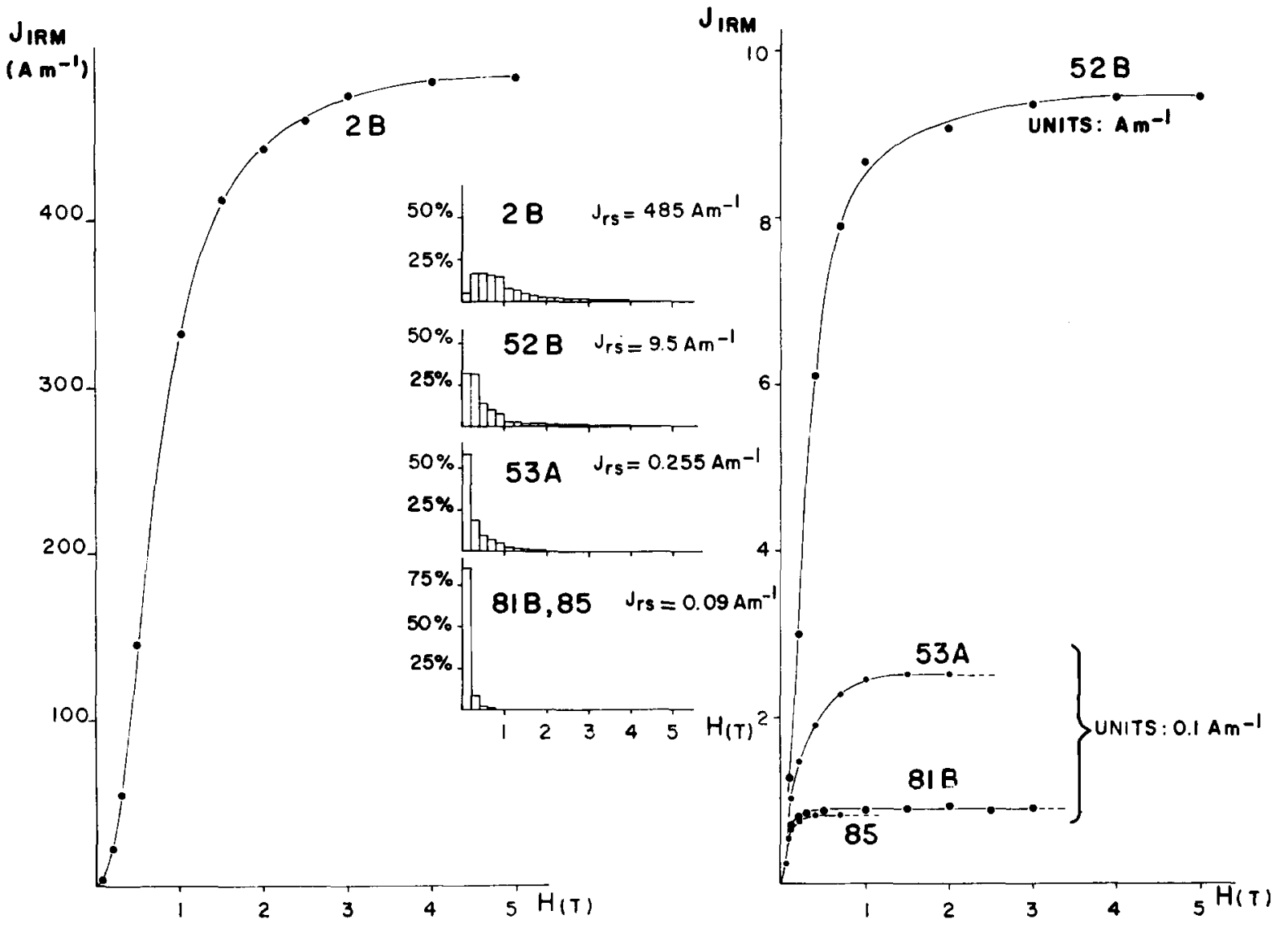

Fig. 4. Acquisition curves of isothermal remanent magnetizations (IRM's) and the corresponding coercivity spectra; large dots are for unleached samples and small dots for samples after chemical treatment. $J$ denotes magnetic intensity, and $J_{\mathrm{rs}}$ is the intensity of the remanence after saturation; the magnetic field values are given in tesla (T). 
similarities as well as differences between red and grey sites. Sample 2B (red site, Fig. 4) reveals a coercivity spectrum typical of hematite, reaching saturation only at $5 \mathrm{~T}$. Samples from the grey sites reveal a correlation between decreasing intensity of saturation magnetization $\left(J_{\mathrm{rs}}\right)$ and a progressive shift of the coercivity spectra towards the lower end, as can be seen for samples 52B, 53A, 81B and 85 . We interpret the lower-coercivity phase in the grey sites as a remanence carrier which is either magnetite or large-grained specularite [28], with site 14 (samples 81 and 85 in Fig. 4) showing the largest amount of this carrier $\left(85 \%\right.$ of the $J_{\mathrm{rs}}$ is acquired by $0.2 \mathrm{~T}$ ). In view of the behavior of these samples during AF, thermal, and chemical demagnetization this lower-coercivity phase is thought to be responsible for the viscous presentday field directions, whereas the characteristic magnetizations in such sites is carried by a highcoercivity, high-blocking temperature phase such as fine-grained hematite.

Below we will discuss the fold test, which is positive, in more detail; nevertheless, it is worth noting here that the mean direction determined for the grey sites (after structural correction) is $D=$ $149^{\circ}, I=+23^{\circ}, \alpha_{95}=6.5^{\circ}$, which is statistically identical to the mean direction for the red sites (after structural correction), with $D=151^{\circ}, I=$ $+19^{\circ}, \alpha_{95}=4.3^{\circ}$. It appears obvious to us, therefore, that the two (red and grey) lithologies have acquired their magnetizations in the same paleofield and probably by the same mechanism, and their magnetizations are consequently of the same age. Grey and red sites can thus be treated without further distinction as one group in the following sections.

\subsection{Bedding error test}

In order to test whether the magnetization of the Red Mountain Formation is of detrital origin, two sites with cross bedding were collected (18 and $19)$, even though we already suspected from the first demagnetization results that the magnetization could well be a chemical remanent magnetization (CRM). Each of these two sites has two sets of samples with a different orientation of foreset dips. The results of the test are presented in Fig. 5,

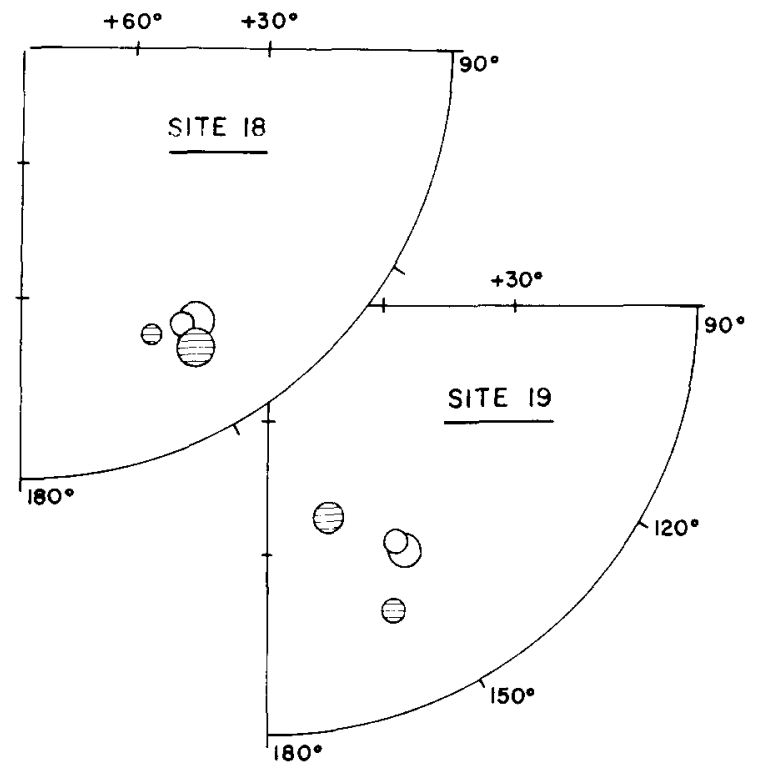

Fig. 5. Stereographic projections (lower hemisphere) of the directions before and after the bedding error test. The circles of 95\% confidence are plotted for the subsets of each site which have different foreset dips, with respect to the paleohorizontal (unshaded, measured at regular layer boundaries), and after a hypothetical correction for foreset dip (shaded; see text for explanation). In both sites, the bedding error test is negative and illustrates that the magnetization was acquired after deposition.

plotted with respected to paleo-horizontal (taken from the overall dip of the strata without cross beds). Following the discussion of Elmore and Van der Voo [14], in which they demonstrated a clear correlation between foreset dip and inclination deviation in the case of inferred detrital remanences (whereas a younger, superimposed CRM does not show such a correlation), our test consists of a comparison between the two subsets of data for each site in two settings: one without any correction (open circles of confidence in Fig. 5), and one with a "correction for foreset dip" (shaded in Fig. 5). It must be noted that this "correction" is hypothetical only, and serves no other purpose than to test whether an inclination deviation exists that correlates with foreset dip. If better inclination agreement exists after "correction", such a correlation is demonstrated, whereas if the results diverge more after "correction" than before, no correlation exists. The results of Fig. 5 show that 


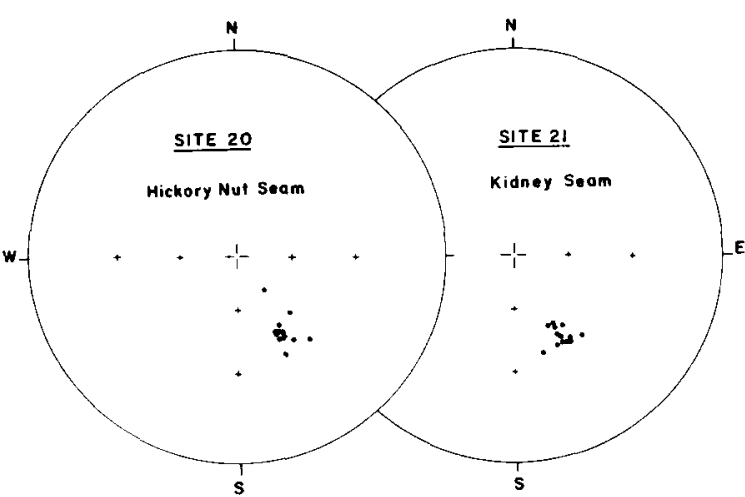

Fig. 6. Stereoplots with the sample directions (uncorrected for structural tilt of the strata) for two sites of conglomeratic beds (lower hemisphere projections). The good clustering of the directions reveals that the magnetization was acquired, probably as a CRM, after deposition.

for both sites, no correlation exists and we can conclude that there is no indication of a bedding error in the magnetization. This, in turn, we interpret as lack of support for a detrital origin for the characteristic magnetizations; it appears that a CRM is more likely than a DRM.

\subsection{Conglomerate test}

To provide further information about the age of the magnetization, two conglomerate layers (sites 20 and 21) were sampled, with a collection of 26 samples from 22 individual pebbles. If the magnetization had been acquired before redeposition of these pebbles, their present magnetic directions would be expected to be random. However, our observations reveal (Fig. 6) that the in-situ magnetic directions are very well clustered at both sites ( $k$ is of the order of 170), and their means are identical to those of the other sites discussed earlier. The test indicates, therefore, that the magnetization was acquired after the deposition of the pebbles, most likely as a CRM, in agreement with our earlier conclusions.

\subsection{Fold test}

Graham's [13] classical fold test has been applied to our results to check whether the magneti-

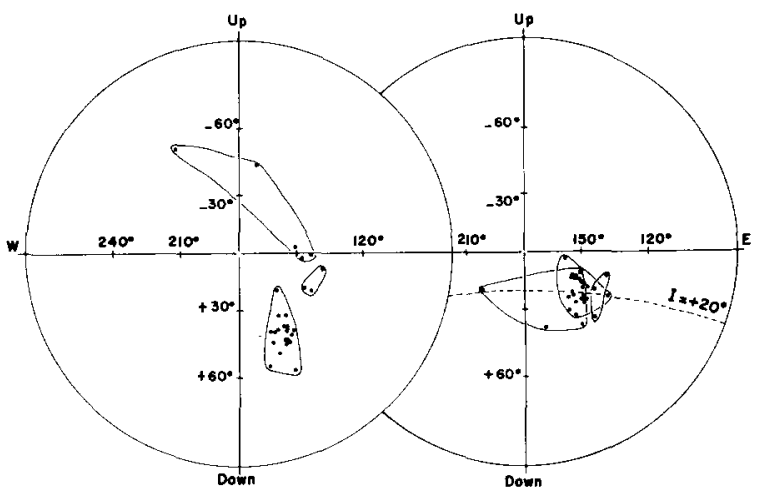

Fig. 7. Stereoplots (note the vertical projection!) of the site-mean directions before (left) and after (right) correction for the tilt of the strata. Envelopes are shown for NW-dipping, SE-dipping and subhorizontal sites. The fold test for this collection is positive, with all directions converging upon a mean direction with a $+20^{\circ}$ inclination (as indicated on the right), indicating that the magnetization was acquired before the Late Carboniferous to Early Permian folding.

zation was acquired before or after the Alleghenian folding (Fig. 7). Excluded from consideration in the test was site 22 , which gave an anomalous southwesterly direction, which we will discuss further below. The precision parameter $k$ increases from 14 to 64 (for $N=27$ entries), which indicates that the results pass the fold test at a significant level with better than $99 \%$ confidence. Consequently, the magnetizations of the Red Mountain Formation were acquired before the Late Carboniferous/Early Permian folding.

Site 22 revealed after structural correction the same inclination as the other sites (Fig. 7), which leads us to suspect complexities in the structural setting as the cause of the declination anomaly. We can rule out the possibility that the magnetization of site 22 is composite: the demagnetization diagrams (chemical as well as thermal) of this site (Fig. 2) show the same univectorial behavior as the other sites. We can also reject the hypothesis of a later complete remagnetization, because the direction does not correspond to any younger known paleofield. We have investigated the possibilities of oroclinal bending (although not seen in the other sites), rotations of a thrust sheet (negated by the directions of other sites) and the possibility of plunging folds. Following Perroud [21] and 
Schwartz and Van der Voo [22], the results have been analyzed by correlation of declination anomalies and structural trends (strikes), and it appears that this correlation is negative: applying a "strike correction" [21] the precision parameter $k$ decreases from 50 to 25 for the eight areas used as independent entries in the analysis. Consequently, we must assume that if the mean direction of site 22 is deviating because of structural complexities, then the vertically dipping strata of this site must have rotated in a plunging fold setting, which is undetectable in the field because of poor outcrop conditions.

Finally, we can conclude that there is no reason to assume that the magnetization was acquired during the folding: dividing the sites into three groups (SE dipping, NW dipping and subhorizontal), it can be seen in Fig. 7 that the fold test is entirely positive. Mean inclinations after structural correction for the three groups are $+19^{\circ},+20^{\circ}$, and $+24^{\circ}$, whereas they are very different before structural correction (Fig. 7).

\section{Conclusions}

A very stable and well-defined magnetization, with $D=150^{\circ}, I=+20^{\circ}$, and $\alpha_{95}=3.5^{\circ}$, is carried by hematite of chemical (diagenetic) origin in the Red Mountain Formation. The hematite is responsible for the designation of iron ore to several seams of this formation, and is demonstrably of secondary origin, occurring as a replacement of former calcite cement and clastic fragments [15]. On the other hand, the magnetization predates the Late Carboniferous/Early Permian folding, so it must be bracketed between Middle Silurian and Early Permian. In order to be able to define the magnetization age more precisely; our only recourse is to compare the paleopole from the Red Mountain $\left(38^{\circ} \mathrm{N}, 132^{\circ} \mathrm{E}, d p=1.9^{\circ}, d m=\right.$ $3.7^{\circ}$ ) with the apparent polar wander path of cratonic North America for the Paleozoic [23]. Assuming that the post-Middle Silurian path is sufficiently characterized, the only period for which the Red Mountain paleopole is compatible with the path is the Late Carboniferous (Fig. 8), which is within the range prescribed by our tests. Thus,

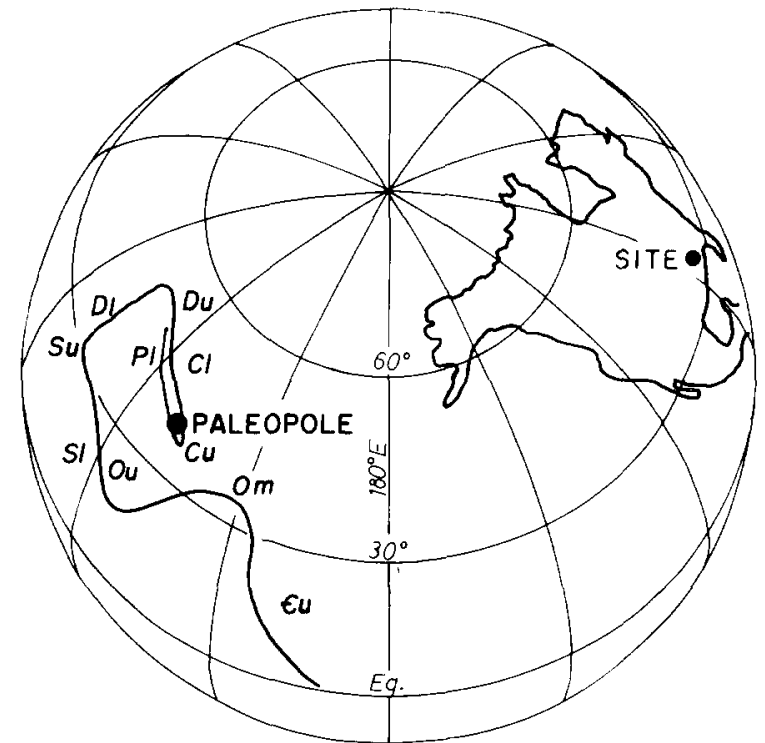

Fig. 8. Comparison of the paleopole for the Red Mountain Formation with the Paleozoic apparent polar wander path of cratonic North America [23], in orthographic projection.

the hematite formation in the iron ores of the Red Mountain Formation would be associated with a Late Carboniferous diagenetic event. It is of interest to note that several other red beds from the Appalachians have yielded probable Late Carboniferous magnetic overprints, in addition to presumably primary magnetizations, such as the Rose Hill [1], and the Juniata [24]. Appalachian carbonates $[25,26]$ as well as the Late Ordovician Neda iron ores in Wisconsin [27] give also similar poles, indicative of extensive remagnetizations during the Late Paleozoic.

It hardly needs emphasizing that our study, furthermore, demonstrates that a fold test alone is not to be taken as conclusive proof of a primary (i.e., syn-depositional) age of the magnetization, nor can the linearity of the demagnetization trajectories or the stability of the magnetization be used for this purpose. Extensive rockmagnetic, opticaland electron microscope studies, in addition to bedding error, conglomerate, or slump tests, remain the only recourse in deciding whether a magnetization is contemporaneous with the deposition age. 


\section{Acknowledgements}

This study was started by Peter M. Brown during the course of his graduate studies at the University, and we thank him for his valuable preliminary work. The postdoctoral fellowship of H. Perroud is gratefully acknowledged, and we thank K. Matson and R.J.E. Johnson for their help and advice in laboratory and field procedures. This study was supported by the National Science Foundation, Earth Science Division, grant EAR 81-03031.

\section{References}

1 A.N. French and R. Van der Voo, The magnetization of the Rose Hill Formation at the classical site of Graham's fold test, J. Geophys. Res. 84, 7688-7696, 1979.

2 D.H. Wilkinson, R. Van der Voo and C. McCabe, Paleomagnetism of Silurian reef limestones in Ohio and Indiana, EOS 62, 271-272, 1981.

3 P. Dankers, Implications of Early Devonian poles from the Canadian Arctic Archipelago for the North American apparent polar wander path, Can. J. Earth Sci. 19, 1802-1809, 1982.

4 G.W. Colton, The Appalachian Basin-its depositional sequences and their geologic relationships, in: Studies of Appalachian Geology, Central and Southern, G.W. Fisher, F.J. Pettijohn, J.C. Reed, Jr. and K.N. Weaver, eds., pp. 5-47, Wiley Interscience, New York, N.Y., 1970.

5 T.D. Cook and A.W. Bally, Stratigraphic Atlas of North and Central America, 272 pp., Princeton University Press, Princeton, N.J., 1975.

6 C.K. Swartz et al., Correlations of the Silurian formations of North America, Geol. Soc. Am. Bull. 53, 533-538, 1942.

7 L.G. Howell, J.D. Martinez and E.H. Statham, Some observations on rock magnetism, Geophysics 23, 285-298, 1958.

8 K.L. Buchan and J.P. Hodych, Paleomagnetism of the Silurian oolitic hematite ores of Birmingham, Alabama, EOS 63, 308, 1982.

9 D.N. Bearce, Origin of conglomerates in Silurian Red Mountain Formation of Central Alabama: their paleogeographic and tectonic significance, Am. Assoc. Pet. Geol. Bull. 57, 688-701, 1973.

10 W.A. Thomas and D.N. Bearce, Measured section, Red Mountain Expressway cut, Birmingham, Alabama, in: Alabama Geol. Soc. 9th Annu. Field Trip Guideb., pp. 231-240, 1971.

11 W.A. Thomas, Evolution of Appalachian-Ouachita salients and recesses from reentrants and promontories in the continental margin. Am. J. Sci. 277, 1233-1278, 1977.

12 R.D. Hatcher, Jr, and A.L. Odom, Timing of thrusting in the southern Appalachians, U.S.A.: model for orogeny?, J. Geol. Soc. 137, 321-327, 1980.
13 J.W. Graham, The stability and significance of magnetism in sedimentary rocks, J. Geophys. Res. 54, 131-167, 1949.

14 R.D. Elmore and R. Van der Voo, Origin of hematite and its associated remanence in the Copper Harbor Conglomerate (Keweenawan), Upper Michigan, J. Geophys. Res. 87, 10918-10928, 1982.

15 M. Cooper, Replacement textures in the Silurian Clintontype iron ores of the Birmingham district, Alabama, $78 \mathrm{pp}$., M.Sc. Thesis, University of Missouri, Rolla, Mo., 1981.

16 M. Cooper and R.D. Hagni, Replacement textures in the Silurian Clintontype iron ores from the Birmingham district, Alabama, Geol. Soc. Am. Abstr. Prog. 13, 430, 1981.

17 J.K. Park, Acid leaching of red beds and the relative stability of the red and black magnetic components, Can. J. Earth Sci. 7, 1088-1092, 1970.

18 S.G. Henry, Chemical demagnetization: methods, procedures and applications through vector analysis, Can. J. Earth Sci. 16, 1832-1841, 1979.

19 J.D.A. Zijderveld, AC demagnetization of rocks: analysis of results, in: Methods in Paleomagnetism, D.W. Collinson, K.M. Creer and S.K. Runcorn, eds., pp. 254-286, Elsevier, Amsterdam, 1967.

20 H.C. Halls, A least-squares method to find a remanence direction from converging remagnetization circles, Geophys. J.R. Astron. Soc. 45, 297-304, 1976.

$21 \mathrm{H}$. Perroud, Relations paléomagnétisme et déformation: exemple de la région de Cabo de Peñas (Espagne), C.R. Acad. Sci. Paris, Sér. II, 294, 45-48, 1982.

22 S.Y. Schwartz and R. Van der Voo, Paleomagnetic evaluation of the oroclinal bending hypothesis in Central and Southern Appalachians, Geophys. Res. Lett. (in press).

23 R. Van der Voo, Paleomagnetism of North America: a brief review, in: Paleoreconstruction of the Continents, Geodynamics Series, 2, M.W. McElhinny and D.A. Valencio, eds., pp. 159-176, Am. Geophysical Union, Washington D.C. and Geological Society of America, Boulder, Colo., 1981.

24 R. Van der Voo and R.B. French, Paleomagnetism of the Late Ordovician Juniata Formation and the remagnetization hypothesis, J. Geophys. Res. 82, 5796-5802, 1977.

25 C.R. Scotese, R. Van der Voo and C. McCabe, Paleomagnetism of the Upper Silurian and Lower Devonian carbonates of New York State: evidence for secondary magnetizations residing in magnetite, Phys. Earth Planet. Inter. 30, 385-395, 1982.

26 C. McCabe, R. Van der Voo, D.R. Peacor, C.R. Scotese and R. Freeman, Diagenetic magnetite carries ancient yet secondary remanence in some Paleozoic sedimentary carbonates, Geology 11, 221-223, 1983.

27 W.F. Kean, Paleomagnetic studies of the rocks at the Ordovician-Silurian boundary in Wisconsin, Geol. Soc. Am. Abstr. Prog. 15, 222, 1983.

28 D.J. Dunlop, Magnetic mineralogy of unheated and heated red sediments by coercivity spectrum analysis, Geophys. J.R. Astron. Soc. 27, 37-55, 1972.

29 J.P. Hodych, R.R. Patzold and K.L. Buchan, Paleomagnetic dating of the transformation of oolitic goethite to hematite in iron ore (submitted to Can. J. Earth Sci.) 